Int. J. Electrochem. Sci., 12 (2017) 10511 - 10523

\title{
A Rapid, Label-free and Impedimetric DNA Sensor Based on PNA-modified Nanoporous Gold Electrode
}

\author{
Wenyan Tao ${ }^{1,2}$, Peng Lin $^{1, *}$, Hong Liu ${ }^{1}$, Shanming Ke ${ }^{1}$ and Xierong Zeng ${ }^{1}$ \\ ${ }^{1}$ Shenzhen Key Laboratory of Special Functional Materials \& Shenzhen Engineering Laboratory \\ for Advance Technology of Ceramics, College of Materials Science and Engineering, Shenzhen \\ University, Shenzhen, China \\ ${ }^{2}$ Key Laboratory of Optoelectronic Devices and Systems of Ministry of Education and Guangdong Pro \\ vince, College of Optoelectronic Engineering, Shenzhen University, Shenzhen, China \\ *E-mail: lin.peng@szu.edu.cn
}

doi: $10.20964 / 2017.11 .38$

Received: 21 July 2017 / Accepted: 1 September 2017 / Published: 12 October 2017

A gold nanoparticle film was successfully prepared on highly ordered and porous anodic aluminum oxide substrate through thermal evaporation deposition technique. As-fabricated nanoporous gold electrode modified by thiol-derivative peptide nucleic acid (PNA) was applied for impedimetric DNA sensing. In-situ kinetic analysis of PNA/DNA hybridization process was realized by electrochemical impedance spectroscopy (EIS) method. Considering the special structure of nanoporous gold electrode, a new equivalent circuit model was proposed for EIS data fitting. The sensitivity of PNA-modified nanoporous gold electrode is $0.4 \Omega / \mathrm{cm}^{2} \cdot \mathrm{nM}$. Meanwhile, complementary DNA target could be detected at concentration as low as $10 \mathrm{nM}$, which indicating that a methodology for rapid, sensitive and label-free detection of DNA has been set-up based on nanoporous gold electrode.

Keywords: anodic aluminum oxide; nanoporous gold electrode; peptide nucleic acid; DNA sensing

\section{FULL TEXT}

(C) 2017 The Authors. Published by ESG (www.electrochemsci.org). This article is an open access article distributed under the terms and conditions of the Creative Commons Attribution license (http://creativecommons.org/licenses/by/4.0/). 